\title{
Do Rich Countries Choose Better Governments?*
}

\author{
COSTAS AZARIADIS AMARTYA LAHIRI \\ University of California, Los Angeles
}

Revised: May 2002

\begin{abstract}
We analyze public investment in social infrastructure using a two-period model in which a government must intermediate all infrastructure investment. Voters choose a government from two alternative types, high quality and low quality. A high quality government obtains higher returns on infrastructure but also demands a bigger consumption payoff for intermediating investment, implying higher taxes for the voting public. We find that these intermediation costs cause threshold effects in the electoral process -- closed economies above a critical level of first period income elect high quality governments while economies below that level elect low quality ones. Thresholds vanish when voters can borrow abroad; capital mobility reduces the current consumption cost of infrastructure investment and favors better quality governments.

We then study the choice of government when government actions are observable with "noise". Small amounts of noise have no effect on the choice of government type or on infrastructure provision. However, once the level of noise becomes large, the agency problem raises the cost of intermediation, reduces infrastructure provision, and biases elections toward low quality governments. Finally, we test the model with cross-country data and find preliminary empirical support for the principal results.
\end{abstract}

JEL Classification: E6, O1

Keywords: Public infrastructure, government quality, intermediation costs, agency costs

Correspondence: Amartya Lahiri, Department of Economics, 8283 Bunche Hall, UCLA, Los Angeles, CA 90095-1477; E-Mail: lahiri@econ.ucla.edu; Phone: (310) 825-8018

\footnotetext{
*We would like to thank, without implicating, seminar participants at Cal State Fullerton, LSE, UC Berkeley, UC Irvine, UCLA, UC Santa Barbara, UC Santa Cruz, University College London, University of Helsinki, University of Maryland, Universitat Autonoma de Barcelona, and Universidad Carlos III de Madrid for helpful comments. Thanks also go to Alan Auerbach and Allan Drazen for asking searching questions, two anonymous referees, the Editor, David Romer, and to Ricardo Adrogue and Laura Alfaro for expert research assistance. The research of both authors was made possible by UCLA Academic Senate Grants.
} 


\section{Introduction}

A number of recent empirical studies have documented that the inequality in the distribution of income between the world's richest and poorest countries has not diminished and has even increased over the past three decades (see Quah (1996), Barro and Sala-i-Martin (1995) and Chari et al. (1995)), despite the convergence predictions of one-sector neoclassical growth models. A particularly troubling event is the poor performance of the least developed countries in subSaharan Africa.

Research on economic growth offers three alternative explanations for this persistent income disparity. The first approach stresses fundamental international differences in technology, demography, economic policy, etc., which could cause countries to gravitate to distinct steady states (e.g., see Barro and Sala-i-Martin (1995) and Mankiw et al. (1992)). The second approach emphasizes the role of history or initial conditions, by constructing models of non-ergodic growth which permit an economy to converge to one of several steady states depending on its initial position (e.g., Galor and Ryder (1989) and Azariadis and Drazen (1990)). The third approach uses models of multiple equilibria to generate asymptotic differences in per capita output independently of initial conditions (e.g., see Matsuyama (1995) and Benhabib and Gali (1995)). An overview of these approaches is in Azariadis (1996).

In this paper we investigate the impact of public infrastructure investment on economic development. The importance of public investment in roads, education, health, communications and the like for economic development has long been acknowledged by development economists. Lately, there have also been attempts to quantify the effect of infrastructure investment on output and growth. Table 1 reports some empirical estimates for the elasticities of output with respect to infrastructure investment. The table also reports the World Bank's computation of the rates of return on infrastructure that are implied by those estimates. Two points about the results are worth noting. First, the estimated returns on infrastructure for developing countries are often higher than the estimates for OECD countries. Second, the estimated rates of return on infrastructure investment for developing countries are strikingly large, often above $60 \%{ }^{1}$

A second key feature of the cross-country data is the systematic disparity across countries in terms of these indicators. Figure 1 plots per capita GNP against four different measures of infrastructure: (a) telephones per thousand population; (b) percentage of population with access to safe water; (c) percentage of households with electricity; and (d) kilometers of roads in good condition per person. All four plots tell a fairly similar tale: infrastructure stocks move in the same direction as per capita income. ${ }^{2}$ While it may not be surprising that poorer countries have lower levels of these infrastructure indicators, what is surprising is that this regularity emerges despite the high measured returns to infrastructure investment. The question that then naturally arises is why don't poorer countries invest more in infrastructure?

\footnotetext{
${ }^{1}$ These results are often critiqued as implying implausibly high returns and overestimating the productivity of infrastructure investment due to omitted variables or mismeasurement. Further, the line of causation is far from clear. While one may debate about the exact magnitudes, the existence of a positive impact of infrastructure on economic development is, in our opinion, a much less contentious issue.

${ }^{2}$ It is important to note, however, that the visual impression of a linear relationship between infrastructure and per capita GNP may be misleading since the axes are logarithmic.
} 


\section{Figure 1: Infrastructure and GNP (in log scales)}

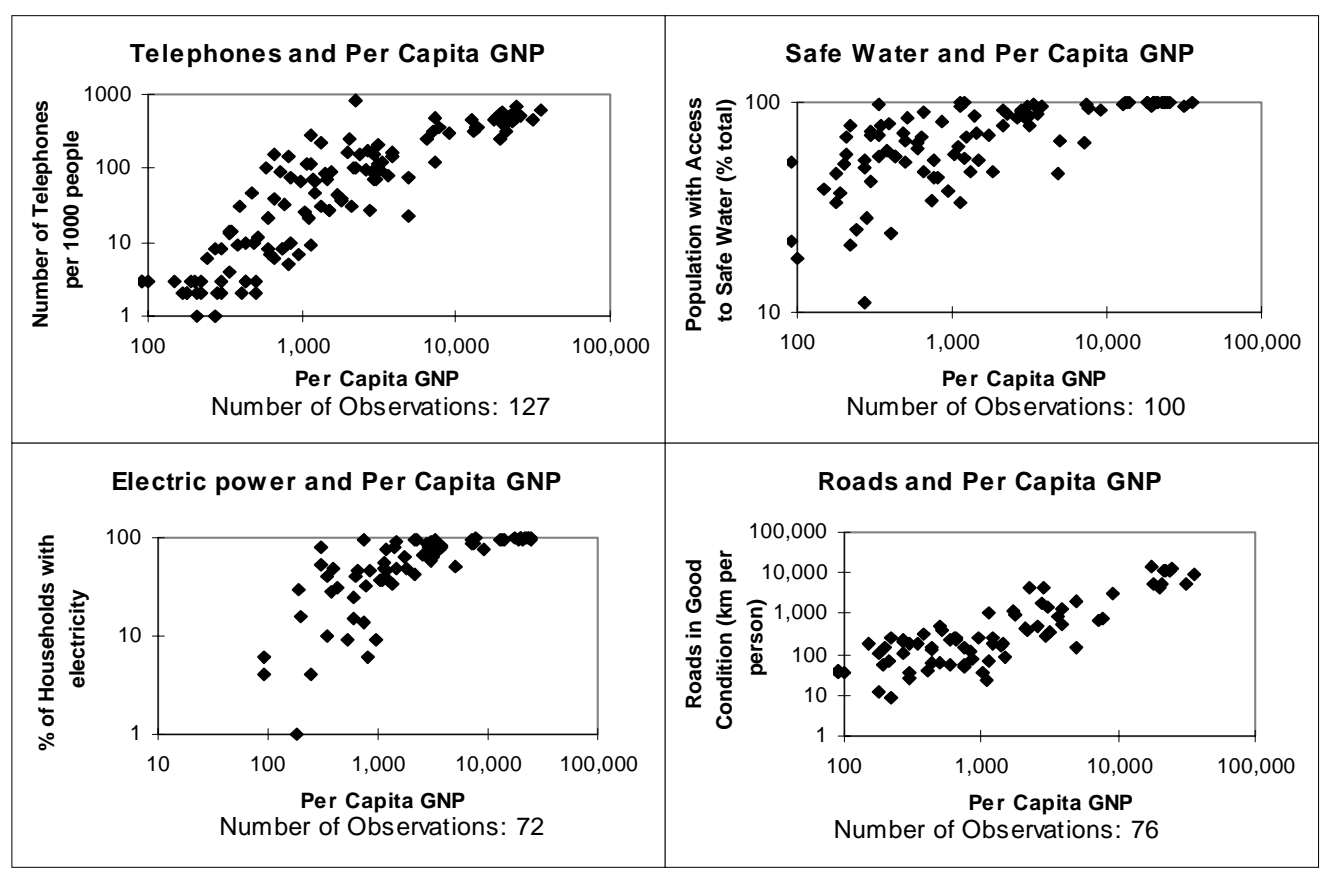

Source: World Development Report 1994, The World Bank. 
Table 1: Studies on Infrastructure Productivity

\begin{tabular}{lccll}
\hline Sample & Elasticity $^{a}$ & $\begin{array}{l}\text { Implied rate }_{\text {of return }}{ }^{b} \\
\text { of }\end{array}$ & Author/year & $\begin{array}{l}\text { Infrastructure } \\
\text { measure }\end{array}$ \\
\hline $\begin{array}{l}\text { United States } \\
\text { Multicountry, OECD }\end{array}$ & 0.39 & 60 & Aschauer 1989 & $\begin{array}{l}\text { Nonmilitary } \\
\text { public capital }\end{array}$ \\
$\begin{array}{l}\text { Multicountry, } \\
\text { developing } \\
\begin{array}{l}\text { Multicountry, } \\
\text { developing }\end{array}\end{array}$ & 0.07 & 95 & Canning and Fay 1993 & Transportation \\
\hline \hline
\end{tabular}

a. Percentage changes in output with respect to a $1 \%$ change in the level of infrastructure

b. Ratio of discounted value of increase in dependent variable to discounted value of investment in infrastructure

Source: World Development Report 1994, The World Bank, Washington D.C., U.S.A.

Beyond the issue of the quantity of infrastructure in developing countries, a further problem is the quality of infrastructure services provided. Thus, the World Development Report (WDR) (1994) reports that, "On average, 40 percent of the power-generating capacity in developing countries is unavailable for production, twice the rate in the best-performing power sectors in low-, middle-, and high-income countries. Half the labor in African and Latin American railways is estimated to be redundant. And in Africa and elsewhere, costly investments in road construction have been wasted for lack of maintenance." (p. 1, WDR 1994).

A fundamental feature of infrastructure provision is the involvement of governments. Most infrastructure investment is intermediated by governments while infrastructure services are, typically, supplied by public utilities and other government agencies. Hence, any discussion of the process of infrastructure provision must take into account the quality of governments. Figure 2 plots an index of bureaucratic efficiency (BE) against per capita GNP. The BE index is taken from Mauro (1995) who constructed it by computing the simple 1980-1983 average of three Business International indices: the judiciary system, red tape, and corruption. The index potentially ranges 
Figure 2

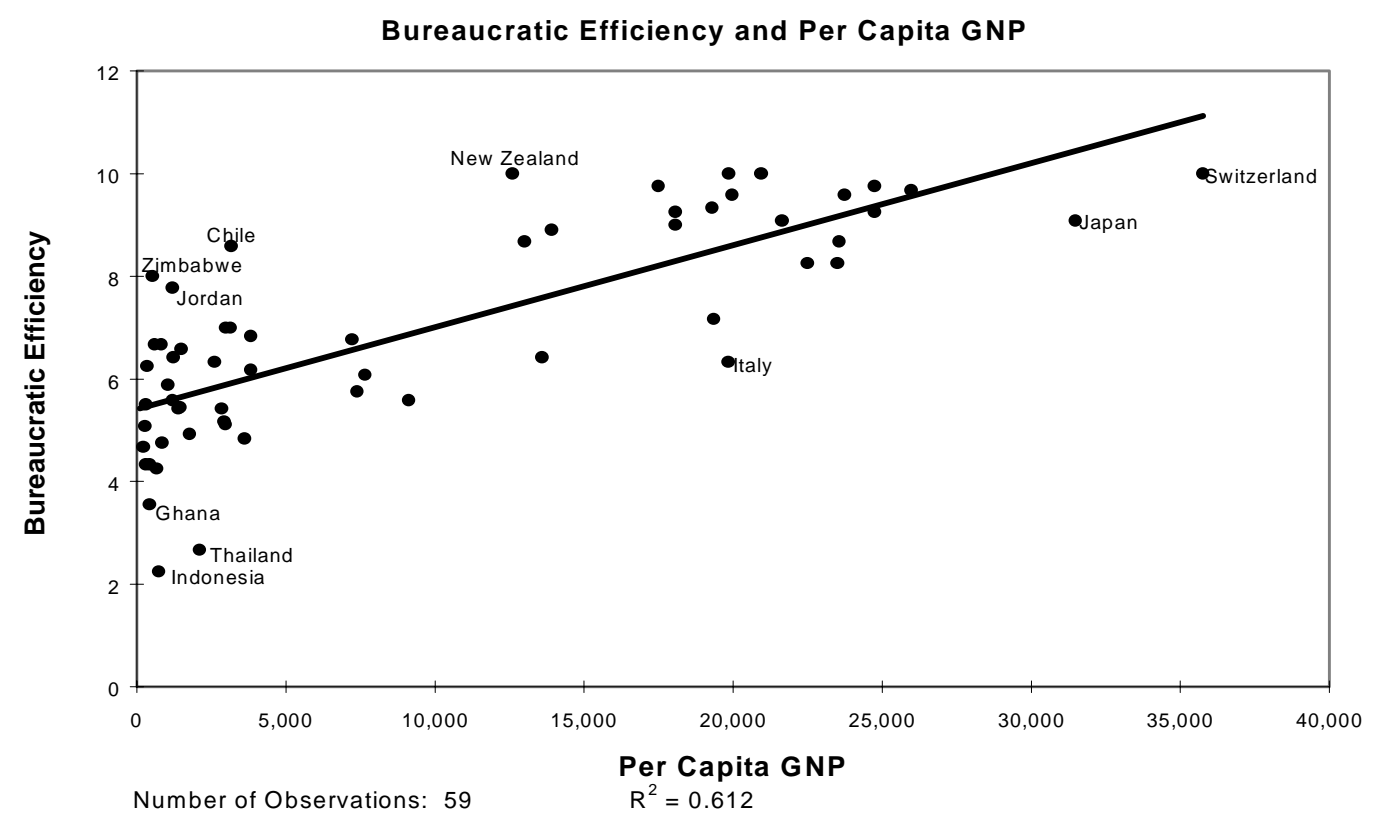

Data Source: Bureaucratic Efficiency from Mauro (1995) 
from zero to ten with a higher value indicating a better functioning bureaucracy. ${ }^{3}$ It is easy to see that richer countries seem to have more efficient bureaucracies. The correlation coefficient between per capita GNP and BE is 0.787 .

The preceding suggests that richer countries have both more efficient governments as well as better infrastructure services. It is important to note that the quality of infrastructure services is unambiguously endogenous to government quality since infrastructure services can only be as good as the quality of the agency which provides it. As returns on infrastructure investment in developing countries are quite high, and as most infrastructure is provided by governments, why then do poorer countries tend to have less efficient governments? In order to answer this question one needs to specify the process by which governments are selected and the incentives facing the public agents who represent the government.

We model public investment in social infrastructure as a two-period principal-agent problem. The "principal" in this model is the voting public who choose their preferred type of government. In addition, they also choose the amount of taxes that they transfer to the government to implement the voters' preferred infrastructure policies. Voters can choose between two types of "agents" -high ability governments and low ability governments. The former type produces higher yields on infrastructure spending than the latter type.

The crucial insight that we bring to bear on the issue of government quality is that high ability governments are also the agents most likely to have access to high paying employment opportunities in the private sector at home and abroad. Hence, in return for efficient intermediation in public projects, high ability governments demand higher consumption which implies a higher tax burden on voters. In this sense, the choice of government by the voting public is essentially one among two alternative time profiles of national consumption: low consumption today and high consumption tomorrow under a high ability government versus the reverse profile under a lower ability government.

In our model, increases in first period income have two important effects on intermediation costs as a proportion of income. First, for a given government type, the unit cost of intermediation declines as long as intermediation costs do not rise proportionately with income. Second, the incremental cost of electing a high ability government also falls. Loosely speaking, as national income rises, governments become "less expensive"; and high income countries find better governments more affordable.

\footnotetext{
${ }^{3}$ Business International (BI) defines the judiciary system as "Efficiency and integrity of the legal environment as it affects business, particularly foreign firms"; red tape as "The regulatory environment foreign firms must face when seeking approvals and permits. The degree to which it represents an obstacle to business"; and corruption as "The degree to which business transactions involve corruption or questionable payments." As an example of the criteria which determine the actual grades that are assigned to a country, a score of 10 on the red tape index indicates a "smoothly functioning, efficient bureaucracy," while a score of 4 indicates "constant need for government approvals and frequent delays." Details on these and other indices collected by BI can be found in Mauro (1995).
} 
We show that these effects introduce two sources of non-convexities into the economy: (a) economies above a threshold level of first period income elect high ability governments while economies below the threshold level elect low ability governments; and (b) the ratio of infrastructure investment to income increases as first period income rises. This, in turn, means that infrastructure investment and second period output also exhibit a threshold effect. Thus, economies which are richer in period one also grow faster. Importantly, these effects appear as long as government costs are nonconvex.

We focus next on the role of private information in infrastructure provision. In particular, we analyze the implications of imperfectly observable government actions. We find that when informational noise is not too large, the electorate selects the same type of government as under public information, and the economy duplicates the complete information outcome. But once the amount of noise becomes sufficiently large, the public intermediation of infrastructure involves an agency cost over and above the standard intermediary costs of government consumption.

This incremental cost depresses investment in infrastructure and biases the choice of government towards the low ability type.

The intuition for this result is that voters base their reelection vote on a noisy signal of the state of the economy. Hence, in some states of the world, the incumbent runs the risk of being voted out of office despite having done the "right" thing. We assume that an ejection from office causes a deadweight cost of government change, i.e., a consumption loss for the government which does not revert to the voters. This possibility means that the incumbent needs to be compensated with some extra consumption in those states of the world where it retains office. The added compensation in good states (or the lost consumption in poor states) is the agency cost of government intermediation under imperfect information; it turns out to be proportional to the reservation consumption of the agent. Hence, agency costs are greater for high ability agents relative to low ability agents.

The two main channels through which the model predicts a movement towards choosing better governments are: (a) the decreasing unit costs of government; and (b) an electorate which is better informed about the economy. In order to examine the plausibility of these channels we examine some cross-country evidence using proxies for the costs of government and for the level of information noise. The data provides preliminary empirical support for both of these channels.

The next section presents the model and a central planning solution. Section 3 discusses how voters choose governments under complete information while Section 4 analyzes the case of imperfectly observable government actions. Section 5 reports some cross-country empirical evidence. Conclusions are in Section 6 and proofs are collected in an appendix.

\section{The Model}

We study infrastructure investment by governments in a two-period lived closed economy in which public capital is the only store of value and capital cannot move across international borders. The economy begins at the start of period 1 and ends at the close of period 2; it is composed of a cohort of identical individuals born at the beginning of period 1 and living for two periods. We normalize

population to one. Members of the cohort maximize the present discounted value of their lifetime utility from consumption, that is,

$$
V=u\left(c_{1}\right)+\beta u\left(c_{2}\right)
$$


where $\mathrm{u}$ is a twice differentiable, increasing and concave function, $\beta>0$, and $c_{i}$ denotes consumption in period $i=1,2$. We assume throughout that $u$ is homothetic, current and future consumption are normal goods, and $-c u^{\prime \prime}(c) / u^{\prime}(c)<1$ for all $c>0$, which makes first and second period consumption gross substitutes.

Each member of the cohort is born with an endowment vector $\left(y_{1}, y_{2}\right) \geq 0$ of a single perishable consumption good in periods 1 and 2 . In order to focus attention on publicly provided infrastructure, we assume that the household cannot store goods privately, i.e., it does not have access to any private storage technology. The only method for transferring income from period 1 to period 2 is through a public storage technology operated by an elected government. ${ }^{4}$ Households use the endowment to consume and pay taxes. The period 1 individual budget constraint is

$$
c_{1}=(1-\tau) y_{1}
$$

where $\tau \in[0,1]$ denotes the tax rate on all first-period income.

In our view there are three important characteristics of the interaction between governments and the value of infrastructure investment to society. First, we believe that public investment in infrastructure increases an economy's production potential. The increased potential output increases potential private income. ${ }^{5}$ Second, the social productivity of infrastructure investment is directly related to the quality (that is, ability and efficiency) of the government making the investment. High quality governments are better able to identify projects with the highest social returns, and to complete them with the lowest amount of resource waste or time waste. Third, public investment in infrastructure necessarily implies intermediation by governments. Public intermediation involves costs for private households because public servants with the highest governing ability are also the ones whose opportunity cost of time is the highest. We build this paper on the commonsense assumption that high quality potential public servants are more likely to attract highly remunerative offers of private sector employment, both at home and abroad, than will lower quality government workers.

Since the quality of public administration is our primary focus here, we ignore issues of government size relative to the population of voters. ${ }^{6}$ In fact, we suppose that there is a fixed number of voters and a fixed-size government elected by the representative voter. The government collects taxes from voters and uses a part of the proceeds to invest an amount, denoted by $g$, in public infrastructure. The tax revenue remaining after infrastructure investment becomes government consumption.

Governments are indexed by $i=H, L$, where $\mathrm{H}$ denotes a high ability type and $\mathrm{L}$ a low ability type. Governments types differ in two respects. First, a type i government is able to

\footnotetext{
${ }^{4}$ This assumption is made for modeling convenience since it simplifies the model considerably. Allowing for private storage does not change the central argument of the paper.

${ }^{5}$ Alternatively, one could view infrastructure investment to be socially beneficial because it increases the expected returns to private savings. This view is complementary to ours but complicates the model needlessly.

${ }^{6}$ Peltzman (1980), and Grier and Tullock (1989) investigate the growth of government outlays in the United States.
} 
convert $g$ units of public infrastructure investment into $m_{i} g$ units of output where $m_{H}>m_{L}>0$. Second, the type $\mathrm{i}$ has a reservation consumption level, $W_{i}$, where $W_{H}>W_{L}>0$. In short, high ability governments raise the rate of return on infrastructure at the cost of higher public consumption.

The reservation consumption level is the consumption level that the government agent can attain in non-governmental employment. Thus, $W_{i}$ is the minimum level of consumption that must be offered to the type i government agent in order to attract her into government service. This implies that $W_{i}$ can be viewed as a wage bill for the government or as an intermediation cost for public investment. We begin by assuming that government type is perfectly observable, and that both types are risk neutral with respect to consumption. Thus, the participation (or individual rationality) constraint for a type $\mathrm{i}$ government is

$$
\tau y_{1}-g \geq W_{i} \quad i=H, L
$$

In period 2 each voter has an endowment $y_{2}$ and receives a transfer $m_{i} g$ from the government, where $i=H, L$ denotes the government type. Thus, the period 2 budget constraint for the representative individual is

$$
c_{2}=y_{2}+m_{i} g
$$

Events in this economy unfold as follows: at the beginning of period 1 the representative household (the median voter) elects a government and chooses the tax rate. ${ }^{7}$ Thereafter, the government collects taxes from the representative agent and chooses $g$. At the end of period $1, g$ is observed by the voter. After observing $g$, the voter decides whether to re-elect the incumbent government. If re-elected, the incumbent gets to consume the tax proceeds left over after the infrastructure provision. If the incumbent is voted out of office, the excess tax revenues are just "wasted". One may rationalize this deadweight loss by recognizing that the process of changing governments absorbs real resources; elections, coups, and revolutions are costly. In period 2 the voter receives a transfer of $m_{i} g$ units of output which she consumes in addition to her endowment $y_{2}$. The economy ends at the end of period 2. The government plays no explicit role in period $2 .^{8}$

The slightly artificial assumption that the incumbent faces an election at the end of period 1 is useful in simplifying the model considerably but still retaining a key feature of any political process. Since the election takes place after the agent observes the level of public investment in

\footnotetext{
${ }^{7}$ Without changing our results, we could have delegated to the government both the choice of the tax rate and the collection of the revenue if both of these acts are observed by the voters. We choose to have the tax rate set by the voters for analytical convenience only.

${ }^{8}$ Our view of the government is that it is an amalgam of politicians and bureaucrats who combine together to provide government services. The assumption that government quality can be changed through elections may seem at odds with the view that bureaucrats are responsible for providing government services since elections, typically, do not alter the pool of bureaucrats. We believe that the efficiency of a given bureaucracy depends on the quality of its political supervisors. Hence, changing the politician through an election is likely to change the quality of the government even if the pool of bureaucrats remains unchanged.
} 
infrastructure, $g$, and government consumption hinges on remaining in power, the electoral process gives the government an incentive to provide the privately desired level of public infrastructure.

We start our analysis by looking at the planning problem in which the social planner chooses the level of infrastructure investment in order to maximize private welfare; intermediation is unnecessary and government consumption is zero. We assume that the social planner can convert infrastructure, $g$, into output at the high rate $m_{H}$.

The planner maximizes the lifetime utility of the representative household, equation (1), subject to the first and second period private budget constraints (equations (2) and (4) respectively) and the public budget constraint $\tau y_{1}=g$. Note that choosing the tax rate, $\tau \in[0,1]$ is equivalent to choosing $g \in\left[0, y_{1}\right]$. The optimal choice of infrastructure is

$$
g^{*}=\arg \max _{g}\left\{u\left(y_{1}-g\right)+\beta u\left(y_{2}+m_{H} g\right)\right\}
$$

If $g^{*} \in\left[0, y_{1}\right]$ is an interior solution, it satisfies the usual first-order condition

$$
u^{\prime}\left(y_{1}-g^{*}\right)=m_{H} \beta u^{\prime}\left(y_{2}+m_{H} g^{*}\right)
$$

Figure 3 depicts the optimal choice of $g$. The production possibility frontier is a straight line with a slope of $-m_{H}$. The optimal amount of infrastructure, $g^{*}$, can be deduced from the point of tangency of the highest indifference curve with the production possibility frontier. In general, the solution for $g$ is given by the saving function

$$
g^{*}=\zeta\left(m_{H}, y_{1}, y_{2}\right)
$$

defined for a representative household with income vector $\left(y_{1}, y_{2}\right)$ and interest yield $m_{H}$. When the utility function is homothetic, the saving function is linearly homogeneous in the income vector $\left(y_{1}, y_{2}\right)$. Hence, we may rewrite equation (6a) in the form

$$
g^{*}=y_{1} \zeta\left(m_{H}, 1, y_{2} / y_{1}\right) \equiv y_{1} z\left(m_{H}, y_{2} / y_{1}\right)
$$

This equation, together with our gross substitutes assumption, says that the ideal amount of infrastructure is an increasing function of the social rate of return, $m_{H}$.

It is easy to see that the scale of the economy has no effect on the $g * / y_{1}$ ratio. By doubling the income vector $\left(y_{1}, y_{2}\right)$ we leave $z$ unchanged, thereby leaving the ratio $g * / y_{1}$ the same as before. Hence, when utility is homothetic, the planning solution in equation (6b) specifies public investment in infrastructure to be a fixed fraction of first period income with no threshold or scale effects. 
Figure 3

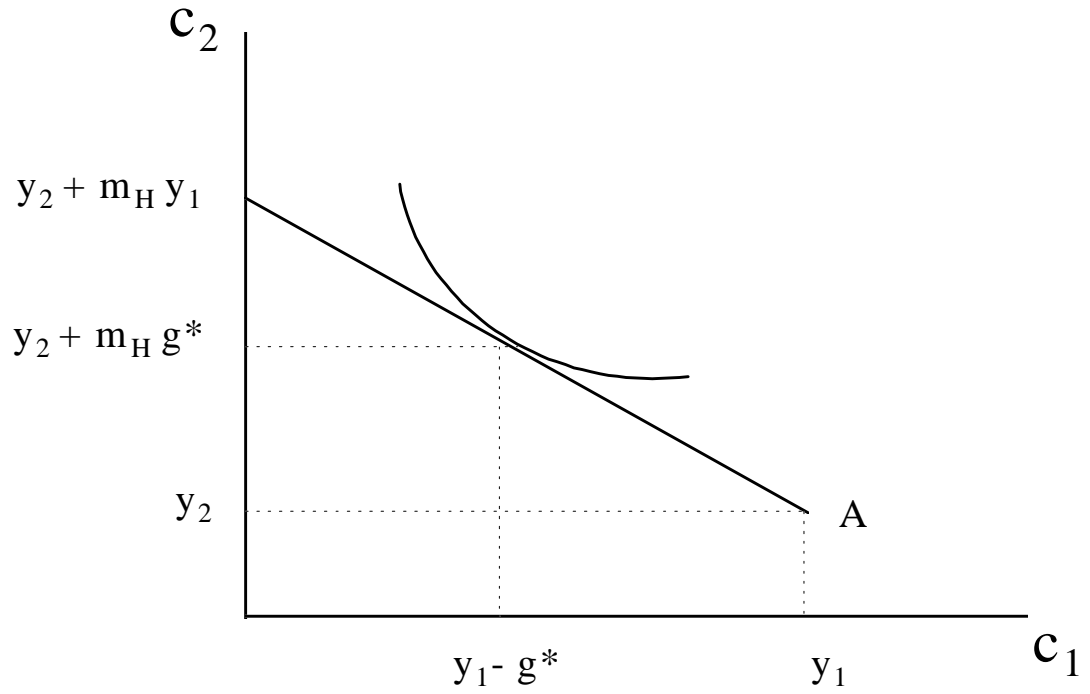

The Planner's optimum 


\section{Costly Government Intermediation}

The planning problem we analyzed in the preceding section assumes that operating costs of running a government are zero. In this section we assume instead that investments in infrastructure are intermediated by policymakers who consume a positive amount of resources while they act as agents of the voting public. Governments come in two possible types -- high quality and low quality. High quality governments cost more than the alternative and produce greater returns on public investment.

We first analyze public and private decisions given the incumbent government type. The actual selection of government can then be inferred by comparing voter welfare levels under each type. In this section the analysis is conducted under the maintained assumption that both the government type and government actions are perfectly observed. We defer to section 4 issues arising from imperfect observability.

\subsection{Choosing a Policy}

Let us first assume that, at the beginning of period 1, a particular government is in power. At the end of that period the household observes the actual infrastructure choice of the government and then decides whether to re-elect the incumbent or to vote her out of office. Thus, the representative voter's decision problem in period 1 is to choose a cutoff level of infrastructure investment, conditional on the incumbent being of type $\mathrm{i}=\mathrm{H}, \mathrm{L}$. We denote this cutoff $g$ by $g_{i}$. Given this value, the voting decision at the end of period 1 follows the simple rule: ${ }^{9}$

$$
\begin{cases}\text { re - elect type i } & \text { if } g \geq g_{i} \\ \text { reject } & \text { otherwise }\end{cases}
$$

If the incumbent is voted out of office, government consumption vanishes and tax revenues in excess of government investment in infrastructure are wasted. However, the complete observability of both the government type as well as the infrastructure provision means that this can never be an equilibrium outcome. In addition, rational governments will not reduce their consumption unnecessarily by spending more on infrastructure than the minimum level desired by voters.

The voter chooses the cutoff to maximize her payoff function, defined by substituting the period 1 and period 2 budget constraints (equations (2) and (4)), as well as the participation constraint for a type i government into the voter's lifecycle utility function. ${ }^{10}$ Specifically, any interior cutoff level satisfies the first order condition

\footnotetext{
${ }^{9}$ This rule must be understood as a commitment by voters that they will not change their mind and vote out of office a government which did invest in infrastructure the minimum required amount. If it were possible for voters to renege, no equilibrium would exist; voters would be indifferent between reneging and keeping their promise while the government would have to forego all consumption if voters reneged.

${ }^{10}$ The participation constraint is binding under complete observability since we have ruled out the possibility of political parties having bargaining power. In the presence of some bargaining power, the participation constraint would not bind even in this complete observability case as the solution would typically split the surplus between the government and the voter.
} 


$$
u^{\prime}\left(y_{1}-g_{i}-W_{i}\right)=\beta m_{i} u^{\prime}\left(y_{2}+m_{i} g_{i}\right)
$$

The voter's maximal lifetime utility when a type i government is in power equals

$$
V^{i}=v\left(y_{1}-W_{i}+y_{2} / m_{i}, m_{i}\right)
$$

where $v(y, R)$ is the indirect utility function corresponding to lifecycle income $y$ and interest yield $R$. When utility is homothetic, the cutoff level equals

$$
g_{i}=\left(y_{1}-W_{i}\right) z\left[m_{i}, y_{2} /\left(y_{1}-W_{i}\right)\right]
$$

The choice of $g_{\mathrm{i}}$ implies voting for a tax rate that is just sufficient to cover infrastructure investment plus the government's reservation consumption. For instance, voters know that a low quality government needs less consumption than a high quality one and makes less effective use of public investment. On the other hand, high quality governments reduce net private income to $y_{1}-W_{H}$ in the first period and, in return, raise the private marginal product of infrastructure in the second period. The incremental cost of good government is $W_{H}-W_{L}$ and the incremental rate of return benefit is $m_{H}-m_{L}$. We assume that $m_{H}>\hat{m}$ where $\hat{m}$ solves

$$
\left(y_{1}-W_{L}\right) z\left[m_{L}, y_{2} /\left(y_{1}-W_{L}\right)\right]=\left(y_{1}-W_{H}\right) z\left[\hat{m}, y_{2} /\left(y_{1}-W_{H}\right)\right]
$$

This assumption ensures that, when consumption goods are gross substitutes, high quality governments will provide a higher level of public investment relative to the low ability type. To finance the higher level of infrastructure and the higher intermediary cost of good government, the public will agree to vote for higher taxes. In other words, $\tau_{H}>\tau_{L}$.

What happens to infrastructure as the scale of the economy increases under a government of fixed ability $i=H, L$ ? Suppose we expand $\left(y_{1}, y_{2}\right)$ by the common factor $\lambda>0$. Then equation (9) says that the proportion of infrastructure investment in first period income is

$$
\frac{g_{i}}{\lambda y_{1}}=\frac{\lambda y_{1}-W_{i}}{\lambda y_{1}} z\left(m_{i}, \frac{\lambda y_{2}}{\lambda y_{1}-W_{i}}\right)=\left(1-\frac{W_{i} / \lambda}{y_{1}}\right) z\left(m_{i}, \frac{y_{2}}{y_{1}-W_{i} / \lambda}\right)
$$

When consumption goods are normal, the saving rate $z$ is decreasing in the second argument which, in turn, is increasing in $\lambda$. Since the cost of government is unaffected by the scale change, the effective saving rate increases with the scale of the economy. This proves

Proposition 1. Assume $g_{i}>0$ for a given quality of government $i=H, L$. Then the ratio of infrastructure to initial income, $g_{i} / y_{1}$ rises as $\left(y_{1}, y_{2}\right)$ expand in proportion.

The intuition for the positive scale effect on the saving propensity $z$ is simple. A proportionate rise in incomes tilts the time profile of the private agent's effective endowment towards period 1 since the first period endowment, $y_{1}-W_{i}$, rises faster than the second period endowment $y_{2}$. 
Note that a rise in $y_{1}$ also reduces the cost of intermediation as a proportion of $y_{1}$. The increased desire to shift consumption towards the future causes voters to raise their desired infrastructure investment $g$. This result continues to hold even if the cost of government increases with the scale of the economy as long as the cost of government grows less than proportionally with the scale of the economy. ${ }^{11}$

The key assumption which drives the result is the constancy of $W_{i}$ and, more broadly, the nonconvex nature of government costs. More generally, the essential elements here are that the cost of government rises less than proportionately with income, and that high ability bureaucrats have to be paid a higher wage than their low ability counterparts. ${ }^{12}$ This assumption seems realistic given the scarcity of skilled labor in poorer countries. Moreover, skilled labor also has a greater ability to migrate to high wage countries which, in turn, should also increase the skill premium in poorer countries. ${ }^{13}$

\subsection{Choosing the Quality of Government}

Having determined the economic implications of each type of government, we can now study the voter's electoral choice. We deduce this choice by comparing the welfare levels that the voter attains under each type of government. At the beginning of period 1 individuals vote according to the simple rule:

$$
\begin{cases}\text { elect type } \mathrm{H} & \text { if } V^{H} \geq V^{L} \\ \text { elect type } \mathrm{L} & \text { otherwise }\end{cases}
$$

Equation (8) reduces this rule to electing type $\mathrm{H}$ if, and only if

$$
v\left(y_{1}-W_{H}+y_{2} / m_{H}, m_{H}\right) \geq v\left(y_{1}-W_{L}+y_{2} / m_{L}, m_{L}\right)
$$

Figure 4 illustrates the factors that affect voting. The effective consumption possibility frontier (CPF) facing the private agent is the kinked contour given by $A C B$, the outer envelope of the two CPF's corresponding to high and low ability governments. If the tangency point of the effective CPF with the median voter's highest indifference curve lies on the CPF of the high ability government then the voter (or representative agent in our model) selects $i=H$. Otherwise, a low quality government is chosen. Note that the flatter the indifference map, the greater the chance that the tangency point lies on the high quality government's CPF. Thus a median voter with a

\footnotetext{
${ }^{11}$ We should note that it is not possible to unambiguously tie down the response of the tax rate to changes in income -- it could rise or fall. However, total tax revenues unambiguously increase as income rises in order to finance the extra infrastructure investment desired.

${ }^{12}$ In this respect, our assumption that these wages are completely fixed and invariant to income is only for analytical simplicity.

${ }^{13}$ Alternatively, we could assume that there are two types of government labor available -- high quality and low quality -- with high quality labor being perfectly mobile across countries. Under the small country assumption, the wage rate for the high quality labor would be fixed by the world wage for that type through a no-arbitrage condition. Importantly, the high quality labor wage would be completely delinked from the domestic economy.
} 


\section{Figure 4}

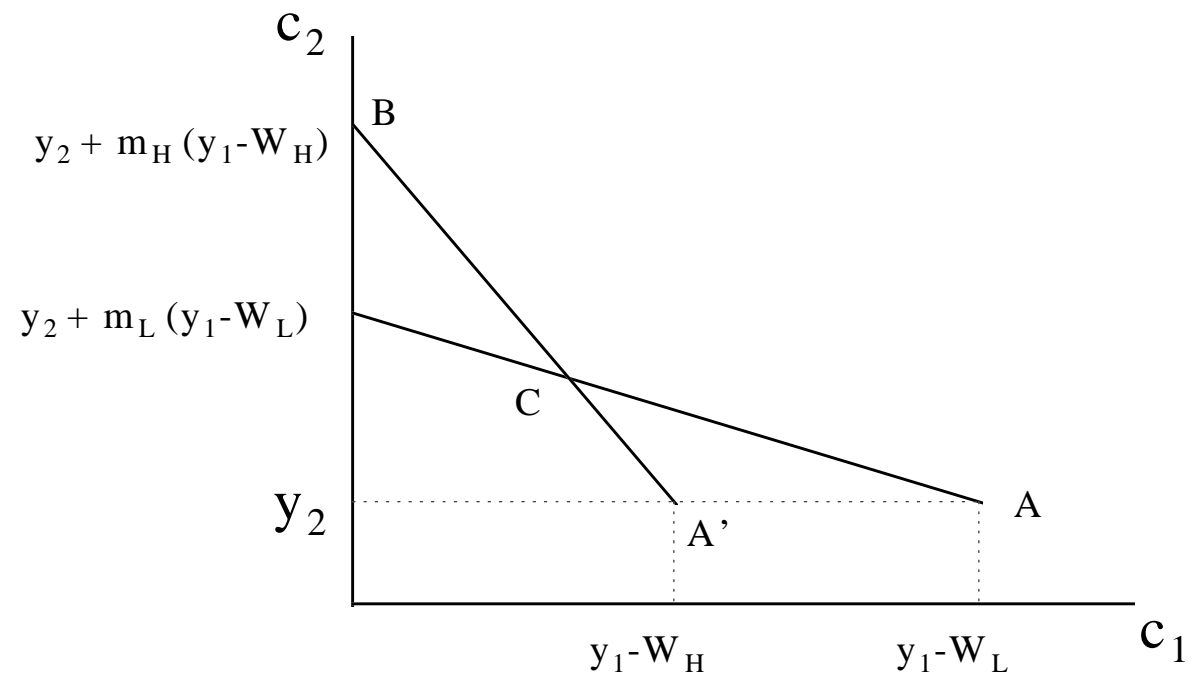

The Voter's Consumption Possibility

Frontiers under the two government types 
high value of $\beta$ is likely to elect a high ability government. It is worth noting here that, if voters could singly or collectively borrow from abroad, the relevant yield would no longer be $m_{H}$ or $m_{L}$, and the CPF in Figure 4 could become convex. We defer this issue to subsection 3.3.

What concerns us most in this section is how national wealth, or the scale of the economy, biases the choice of government. In particular, are richer economies more likely to have high ability governments? If that is so, then rich countries will invest in infrastructure a larger fraction of their income and, consequently, experience faster growth in consumption and output than will poor countries. To study this issue, we narrow the voter's utility function down to the iso-elastic class

$$
u(c)= \begin{cases}c^{1-\theta} /(1-\theta) & \text { if } \theta \in[0,1) \\ \log c & \text { if } \theta=1\end{cases}
$$

Without further loss of generality, we normalize the income vector $\left(y_{1}, y_{2}\right)$ to $(\lambda, \lambda y)$, the cost of government $\left(W_{L}, W_{H}\right)$ to $(0, w)$, and require socially desired infrastructure to be non-negative for each type of government. Infrastructure will be non-negative if

$$
\beta m_{L}>y^{\theta}, \quad \beta m_{H}>[\lambda y /(\lambda-w)]^{\theta}
$$

Denoting the present discounted value of lifetime income by $Y$, it is easy to check that under equation (13), the indirect utility function, $v(Y, R)$, of the representative voter is

where

$$
\begin{gathered}
(1-\theta) v(Y, R)=Y^{1-\theta} g(R) \\
g(R) \equiv[R /(\gamma+R)]^{1-\theta}+\beta[\gamma R /(\gamma+R)]^{1-\theta} \\
\gamma=(\beta R)^{1 / \theta}, \quad R=m_{i}, \quad i=H, L
\end{gathered}
$$

From this indirect utility function we readily obtain the voter's lifecycle utility under each government, given the normalized income vectors $(\lambda, \lambda y)$ and government consumption $\left(W_{L}, W_{H}\right)=$ $(0, w)$. The relevant expressions are

$$
\begin{gathered}
(1-\theta) V^{L}(\lambda)=\left(\lambda+\lambda y / m_{L}\right)^{1-\theta} g\left(m_{L}\right) \\
(1-\theta) V^{H}(\lambda)=\left(\lambda-w+\lambda y / m_{H}\right)^{1-\theta} g\left(m_{H}\right)
\end{gathered}
$$

where $\lambda>0$ is the scale parameter. The initial scale of the economy corresponds to $\lambda=1$.

In order to simplify the notation, we define the payoff ratio

$$
\psi(\lambda) \equiv V^{H}(\lambda) / V^{L}(\lambda)
$$

Since $V^{H}>0$ and $V^{L}>0$ by assumption, the median voter elects the high quality government if $\psi \geq 1$, the low quality government otherwise. To see how the scale of the economy influences the electoral prospects of the two alternative types of governments, we collect some useful properties of the function $\psi$ in the following Lemma (the proof of which is obvious): 
Lemma 1. $\psi$ is monotonically increasing in $\lambda$ for all $\lambda \geq w /\left(1+y / m_{H}\right)$.

Lemma 1 says that an increase in the scale of the economy weakens the lower-cost advantage of a low ability government and undermines its attractiveness to the voter relative to a high ability government. This occurs because a rise in $\lambda$ causes the lifecycle income net of intermediation cost, $\lambda-w+\lambda y / m_{H}$, under a type $\mathrm{H}$ government to rise by more than the corresponding increase under a type L government. From this Lemma we also obtain a definition of the critical scale $\lambda^{*}$ above which good governments are elected.

Lemma 2. Let $\alpha=\left[g\left(m_{L}\right) / g\left(m_{H}\right)\right]^{1 /(1-\theta)}$ and assume that $y<(1-\alpha) m_{H} /\left[\left(\alpha m_{H} / m_{L}\right)-1\right]$. Then there exists a critical scale of the economy, $\lambda^{*}$, such that $\psi(\lambda) \geq 1, \forall \lambda \geq \lambda^{*}$.

Proof. The proof is straightforward once we note that $\lambda^{*}$ solves $\psi(\lambda)=1$.

Lemma 2 shows that all economies whose endowment ratio $y_{2} / y_{1}(=y)$ is sufficiently skewed toward the first period have a critical size $\lambda^{*}$ above which they elect good governments. This leads directly to our second proposition.

Proposition 2. For a given y, all economies with scale greater than the critical endowment vector $(\lambda *, \lambda * y)$ elect high quality governments which invest in public infrastructure a greater fraction of first-period income than do low quality governments. Economies below the critical scale elect low quality governments, invest less and grow at a slower rate.

Proposition 2 shows that the per capita income of an economy has a major influence on the kind of government that the median voter elects. High income countries are more likely to elect high quality governments since the incremental cost of good government absorbs a smaller fraction of national income. This implies that the decreasing costs of good government introduce threshold effects into economic development since high ability governments favor economic growth.

This proposition predicts that investment should behave as in Figure 5. In the figure, public investment is small and rises at a low rate until $\lambda=\lambda *$. Once we reach that threshold, the median voter elects the high quality government which causes infrastructure investment to jump discontinuously. Thereafter, infrastructure spending rises at a faster rate. Correspondingly, the ratio of infrastructure investment to first period income rises over time to approach a constant as the initial endowment becomes infinitely large.

Our result suggests a political economy explanation for poverty traps. In general, poorer economies find the incremental cost of high quality government too steep relative to the benefit good government confers, e.g., a better rate of return on the meager amount of aggregate saving. The rational choice instead is a low quality government which invests very little in socially productive projects such as public infrastructure, health, education, etc.. In turn, low investment prevents rapid growth in output and income, perpetuating the tenure of low ability governments. This vicious cycle is broken only if the economy attains a certain critical level of 
Figure 5

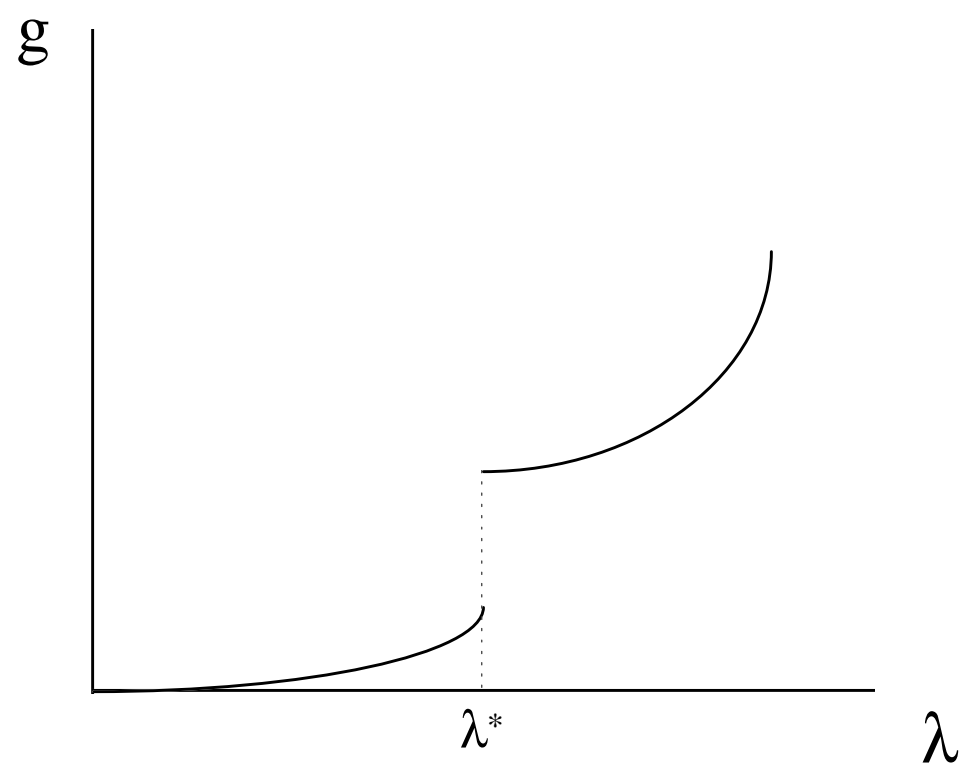

Equilibrium response of infrastructure investment to changes in first period income 
income. At that point the regime switches to a "virtuous" cycle, with high ability governments investing heavily in socially productive projects and rapid growth. ${ }^{14}$

\subsection{Open Economy Issues}

The choice of government is greatly influenced if the voters of a small open economy are able to smooth consumption by borrowing or lending abroad at some fixed yield R. This possibility means that investment in infrastructure need not reduce current consumption exclusively but may, instead, be paid for out of future consumption. It is not hard to see why this form of perfect capital mobility reduces the current consumption cost of good governments and makes them more attractive to voters.

As a technical matter, capital mobility allows voters to convexify their budget sets and reduce or eliminate the threshold properties of the nonconvex consumption possibility frontiers which arise in the closed economy case. To keep under control the number of cases we need to study, we make two sensible assumptions about small economies:

(a) Some infrastructure is desirable in a small open economy; and

(b) Voters in a closed economy will choose a high quality government if they are sufficiently patient.

Assumption (a) means that $\mathrm{R}$ is sufficiently below $m_{H}$ and $m_{L}$ so that individuals do not wish to smooth consumption purely by engaging in foreign lending without building any infrastructure at home. Assumption (b) means that $m_{H}$ is sufficiently greater than $m_{L}$ and, specifically:

$$
m_{H}\left(y_{1}-W_{H}\right)>m_{L}\left(y_{1}-W_{L}\right)
$$

This says that a high quality government generates higher second period consumption for any society that defers all its consumption until the second period.

Under this structure, a government of type $\mathrm{i}=\mathrm{L}, \mathrm{H}$ is associated with the consumption possibility frontier

$$
c_{1}+c_{2} / R \leq(1 / R)\left[y_{2}+\left(y_{1}-W_{i}\right) m_{i}\right]
$$

if we suppose that the foreign yield $\mathrm{R}$ satisfies $R<m_{L}<m_{H}$. The resulting consumption possibility frontiers are graphed in Figure 6 which demonstrates clearly that good governments will be elected because they uniformly produce bigger consumption sets for voters. Note that the graphed consumption possibility frontiers under open economies theoretically go all the way to the horizontal axis.

\footnotetext{
${ }^{14}$ It is important to point out that the problem highlighted here is similar to the problem facing an investment bank which is hiring a portfolio manager. If superior managers (who generate high returns) have higher reservation wages then the bank will hire a high quality manager only if its portfolio is large enough. For a small portfolio, the high fixed cost of hiring good managers will prove to be too expensive and the firm will hire lower quality personnel and accept the lower returns that come with these managers. In this environment, one would observe that the big investment banks with large portfolios are also the ones which generate high returns.
} 


\section{Figure 6}

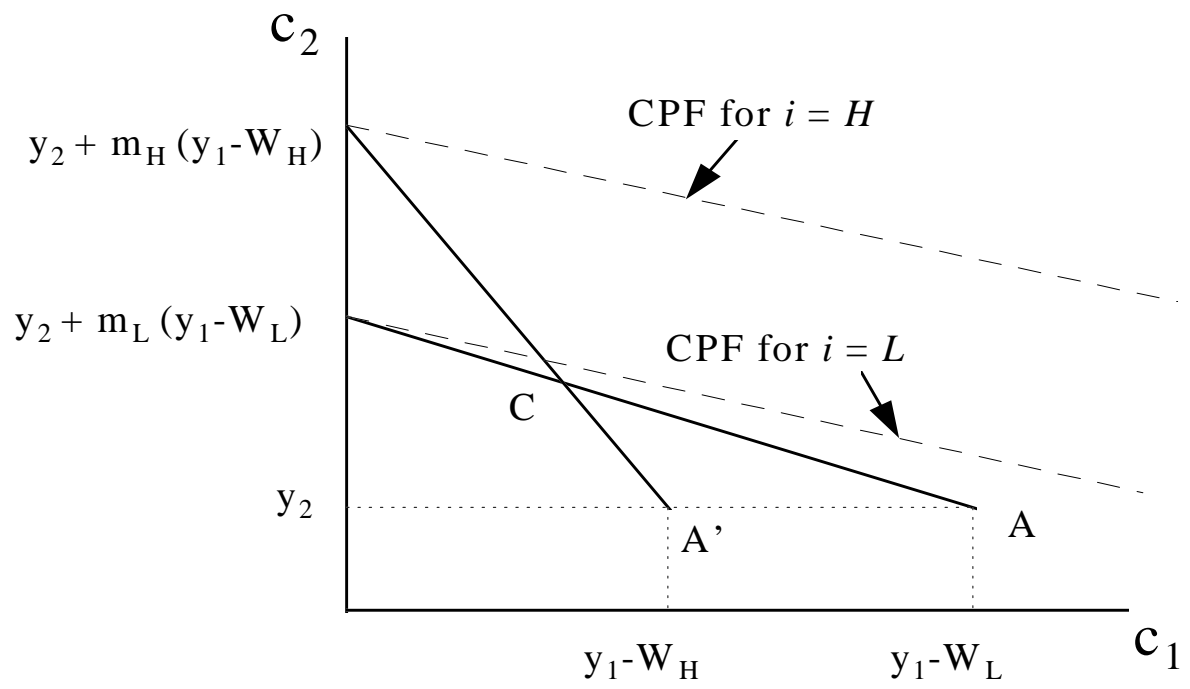

The Voter's Consumption Possibility

Frontiers in closed and open economies 


\section{Agency Costs in Infrastructure Investment}

An issue that is often raised in the context of public investment as well as electoral processes is the observability of government actions. If government actions cannot be perfectly observed and information is noisy, then there is a secondary reason for agency costs in the process of public investment. In particular, the more noisy the information process, the higher the chances of an incumbent government being voted out. In such environments, government agents would demand a markup over their reservation outside wages as compensation for the electoral risk. If this markup rises with the outside option then a noisy information process is likely to make high ability agents even more expensive and should make it more likely for poorer countries to elect low quality governments. In this section we formalize this idea.

In the analysis in the previous sections, we have assumed that households can costlessly observe both the government type and the amount of infrastructure investment, $g$, that is made by the government in period 1. We now relax this assumption by allowing for private information. We assume that the voter can neither observe the true government type nor the amount that the government invests in infrastructure. ${ }^{15}$

The sequence of events for the economy is the same as in the full information case above. The only difference is that at the end of period 1 the household observes a noisy signal of infrastructure investment, $m g$, rather than $m g$ itself. Specifically, the household observes $s_{i}$ which is given by

$$
s_{i}=m_{i} g_{i}+\varepsilon \quad i=H, L
$$

We assume that $\varepsilon$ is an independent, identically distributed random variable which is uniform over the interval $[-a, a]$. Two features of this specification are worth noting. First, we assume that the signal, $s_{i}$, is directly correlated with the government type, $m_{i}$. This assumption is needed for the existence of separating contracts. Second, since the expected value of $\varepsilon$ is zero, $E\left(s_{i}\right)=E\left(m_{i} g_{i}\right)$ where $E$ is the expectations operator. Hence, the assumed imperfect observability can be interpreted as pure noise. An increase in $a$ causes an increase in the variance of $\varepsilon$ and hence, a less informative signal.

The solution method for this problem is similar to the complete information case. The voter's decision problem in period 1 is to choose a cutoff value for the signal, $\hat{s}_{i}$, and a tax rate, $\tau_{i}$. Given the cutoff value for the signal, the voting decision at the end of the period is given by the simple rule

$$
\begin{cases}\text { re - elect the incumbent } & \text { if } s \geq \hat{s}_{i} \\ \text { reject } & \text { otherwise }\end{cases}
$$

As before, the government gets to consume only if it is re-elected. In the event that the incumbent is voted out of office, government consumption is zero and tax revenues in excess of government investment are wasted. In equilibrium, this wastage has positive probability since the

\footnotetext{
${ }^{15}$ We need imperfect observability of both government type and infrastructure investment. As will be made clearer below, either of these variables is a sufficient statistic for the other.
} 
voter could observe a low signal despite the incumbent doing the "right thing". This is a departure from the complete information case where voting out the incumbent could never be an equilibrium outcome. As will be clear below, the potential wastage of tax revenue under private information is a positive agency cost of government.

A contract between the voters and a government of type $i$ is the vector $\sigma_{i}=\left(\tau_{i}, \hat{s}_{i}\right)$. Given a contract $\sigma_{i}$, a type $i$ government chooses $g$ to maximize expected consumption which is given by

$$
W\left(\sigma_{i}, m_{i}\right)=\left\{\operatorname{Pr}\left(s_{i} \geq \hat{s}_{i}\right)\left(\tau_{i} y_{1}-g_{i}\right)\right\}
$$

where $\operatorname{Pr}\left(s_{i} \geq \hat{s}_{i}\right)$ denotes the probability of the signal exceeding the cutoff. ${ }^{16}$ Equation (20) and the assumed uniform distribution for $\varepsilon$ lead to

$$
\operatorname{Pr}\left(s_{i} \geq \hat{s}_{i}\right)= \begin{cases}0 & \text { for } m_{i} g_{i} \leq \hat{s}_{i}-a \\ \frac{m_{i} g_{i}+a-\hat{s}_{i}}{2 a} & \text { for } m_{i} g_{i} \in\left[\hat{s}_{i}-a, \hat{s}_{i}+a\right] \\ 1 & \text { for } m_{i} g_{i} \geq \hat{s}_{i}+a\end{cases}
$$

The solution to the government's problem, $\hat{g}_{i}$, is given by

$$
\hat{g}_{i}\left(\sigma_{i}, m_{i}\right)=\underset{g}{\arg \max }\left\{\left[\operatorname{Pr}\left(s_{i} \geq \hat{s}_{i}\right)\right]\left(\tau_{i} y_{1}-g\right)\right\}
$$

where the optimal $g$ is chosen subject to $g \in\left[0, \tau_{i} y_{1}\right]$ and equation (22a).

At the beginning of period 1 the household offers either a type $H$ or a type $L$ contract, i.e., either $\sigma_{H}$ or $\sigma_{L}$. The actual contract offered is determined by a comparison of the relevant payoffs. In particular,

$$
\sigma_{i}= \begin{cases}\sigma_{H} & \text { if } V^{H} \geq V^{L} \\ \sigma_{L} & \text { otherwise }\end{cases}
$$

where $V^{i}$ denotes the lifetime utility of the private agent under a type $i$ contract. Efficient contracts, $\sigma_{i}=\left(\tau_{i}, \hat{s}_{i}\right)$ have to be on the utility possibility frontier of the representative voter and the type i government. All such contracts maximize the voter's lifetime welfare (equation (1)) subject to the equilibrium schedule for infrastructure investment (equation (22b) above) and the constraints:

\footnotetext{
${ }^{16}$ This contract is slightly different from the standard principal-agent contract because the payment to the agent (the government) does not depend continuously on the signal, s. In our setting the output produced by the infrastructure investment is not observed until after the agent has consumed. Otherwise, the contract could stipulate a payment schedule which depended continuously on the observed output.
} 


$$
\begin{array}{ll}
\hat{W}\left(\sigma_{i}, m_{i}\right) \geq W_{i} & i=H, L \\
\hat{W}\left(\sigma_{i}, m_{j}\right) \leq W_{j} & j \neq i, j=H, L
\end{array}
$$

where $\hat{W}$ is expected government consumption when $g$ is chosen optimally by the government $i$ given any contract $\sigma_{i}$. Equation (23) is the participation constraint for a type $i$ government; it says that the expected consumption for a type $i$ government under a type $i$ contract must match or exceed that type's reservation consumption level. Equation (24) is the incentive compatibility constraint which states that, under an efficient contract, a type $j$ government agent should not find it in her best interest to accept a type $i \neq j$ contract for each $i=H, L$ and $j=H, L$. Put differently, equation (24) is the "truth telling" constraint which ensures that the reservation wage (or outside option) of a type $j$ agent is at least as much as the expected consumption from accepting a contract designed for a type $i$ agent. This rules out pooling equilibria.

Using equations (22) - (24) we deduce some basic characteristics of optimal government behavior. First, we can never have $m_{i} g_{i} \leq \hat{s}_{i}-a$ in equilibrium since it implies a zero probability of re-election and $\hat{W}=0$. But this is ruled out by the participation constraint. Second, it can never be optimal for a type $i$ government to invest more than $\frac{\hat{s}_{i}+a}{m_{i}}$ since re-election is a certainty event for all $g_{i} \geq \frac{\hat{s}_{i}+a}{m_{i}}$ while $W\left(\sigma_{i}, m_{i}\right)$ is a decreasing function of $g_{i}$. Third, for $m_{i} g_{i} \in\left[\hat{s}_{i}-a, \hat{s}_{i}+a\right]$ the agent's optimal choice of $g$ is

$$
\hat{g}_{i}=\frac{m_{i} \tau_{i} y_{1}+\hat{s}_{i}-a}{2 m_{i}}
$$

Equation (25) is obtained by using equation (22a) to maximize expected government consumption within the range specified by equation (22b). Substituting (25) into (21) we find the maximized expected consumption of the type $i$ government:

$$
\hat{W}\left(\sigma_{i}, m_{i}\right)= \begin{cases}0 & \text { for } m_{i} g_{i} \leq \hat{s}_{i}-a \\ \frac{\left(m_{i} \tau_{i} y_{1}+a-\hat{s}_{i}\right)^{2}}{8 m_{i} a} & \text { for } m_{i} g_{i} \in\left[\hat{s}_{i}-a, \hat{s}_{i}+a\right] \\ \tau_{i} y_{1}-\frac{\hat{s}_{i}+a}{m_{i}} & \text { for } m_{i} g_{i} \geq \hat{s}_{i}+a\end{cases}
$$

In order to derive our results it is convenient to define the auxiliary parameters:

$$
\begin{aligned}
\tau^{*} & \equiv \frac{\left(z_{H}-z_{L}\right) a^{1 / 2}}{\left(m_{H}-m_{L}\right) y_{1}} \\
z_{i} & \equiv\left(8 m_{i} W_{i}\right)^{1 / 2}
\end{aligned}
$$


These parameters help us express some properties of efficient contracts:

Lemma 3. Any efficient contract for a type $i$ government, $\sigma_{i}=\left(\tau_{i}, \hat{s}_{i}\right), i=H, L$, satisfies (a) $\tau_{H} \geq \tau^{*} \geq \tau_{L}$; (b) $\hat{W}\left(\sigma_{i} ; m_{i}\right)=W_{i}$; and (c) $\hat{W}\left(\sigma_{i} ; m_{j}\right)<W_{j}, \quad i \neq j, i, j=H, L$.

Proof. See the Appendix.

Lemma 3(a) means that any efficient contract for the high quality government must give the type $\mathrm{H}$ government sufficiently high tax revenues relative to the type $\mathrm{L}$ government. Note that a similar result can also be proved for $m_{i} g_{i} \geq \hat{s}_{i}+a$. Lemma 3(b) and 3(c) states that the participation constraint for type $i$ always binds while the incentive compatibility constraint for type $j, j \neq i$, never binds under any efficient type $i$ contract. This result simplifies the problem considerably since we can ignore the incentive compatibility constraint altogether as we derive the voter's decision rules for the cutoff value of the signal and the tax rate.

Figure 7 depicts the participation (P) and incentive compatibility (I) constraints for a type $\mathrm{H}$ contract in $(\tau, \hat{s})$ space for $m_{i} g_{i} \in\left[\hat{s}_{i}-a, \hat{s}_{i}+a\right)$. The two constraints intersect at $\tau=\tau *$. The $\mathrm{P}$ constraint has a smaller intercept $\left(a-z_{H} a^{1 / 2}<a-z_{L} a^{1 / 2}\right)$ but a greater slope relative to the I constraint $\left(m_{H} y_{1}>m_{L} y_{1}\right) .{ }^{17}$ All feasible contracts must lie to the right of the P constraint and to the left of the I constraint. Thus, the non-empty region of feasible contracts for the type $\mathrm{H}$ government is characterized by $\tau>\tau *$. Since the consumer is always better off with lower taxes and higher target signals, it is optimal for the median voter to reduce taxes until the point where the participation constraint just binds while the incentive compatibility constraint is non-binding.

Lemma 4. All contracts $(\tau, \hat{s})$ for which the participation constraint for the type $i$ contract just binds are also contracts for which the incentive compatibility constraint for the type $j$ contract just binds, for $i \neq j, i, j=H, L$.

Proof. See the Appendix.

Lemma 4 in combination with Lemma 3(b) and 3(c) says that the space of all possible efficient contracts can be characterized with only two constraints. Figure 7 also shows that all type L contracts must belong to the non-empty set of points lying to the left of line $\mathrm{P}$ and to the right of line $\mathrm{I}$, i.e., for $\tau<\tau *$. Note that by Lemma 4, the line depicting the $\mathrm{P}$ constraint for the type $\mathrm{H}$ contract is also the line which depicts the I constraint for the type L contract.

Lemma 5. $m_{i} g_{i}=\hat{s}_{i}+a$ if and only if $a \leq \frac{m_{i} W_{i}}{2}, i=H, L$.

Proof. See the Appendix.

Lemma 5 reveals that if the level of noise (or the extent of information imperfection) is smaller than some critical level, then a type $i$ government would choose to insure itself fully against being voted out of office by pushing infrastructure investment to the point where the signal observed by the median voter could never fall below the cutoff stipulated by the contract. For values of $a$

${ }^{17}$ Figure 6 has been drawn under the maintained assumption that the two constraints intersect each other in the positive quadrant, i.e., $(\tau, \hat{s})>0$. 


\section{Figure 7}

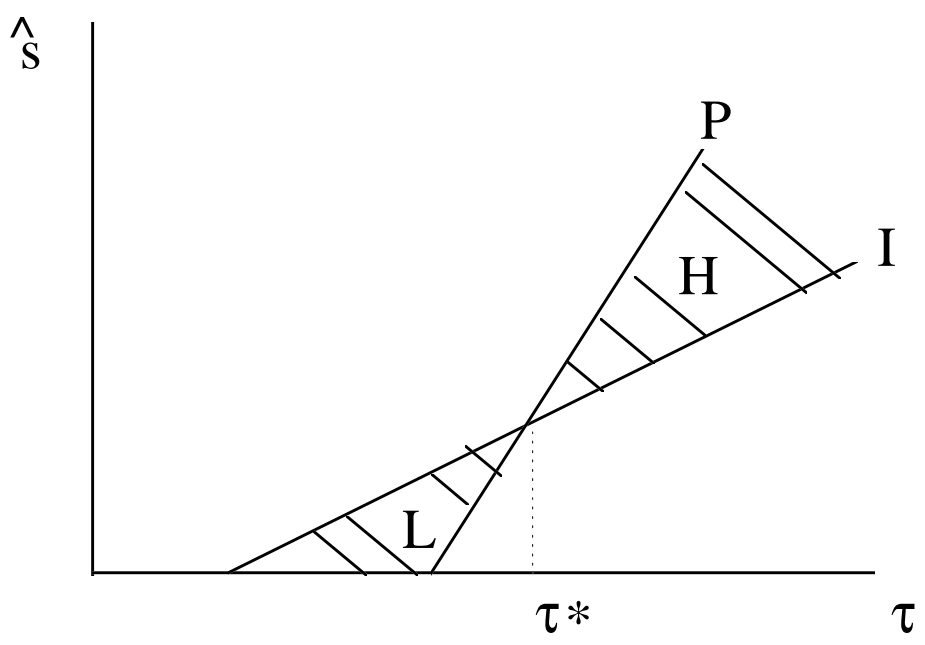

The Participation and Incentive Compatibility constraints of the two types of contracts 
exceeding this critical level, the equilibrium provision of $g$ would be less than the full insurance level, and the probability of re-election, in equilibrium, would be less than one.

Since $a$ is public information, the economy will reproduce the certainty outcome derived earlier when $a \leq \frac{m_{i} W_{i}}{2}, i=H, L$. In this case we must have $\tau_{i} y_{1}-\frac{\hat{s}_{i}+a}{m_{i}}=W_{i}$ since, by Lemma 3, the participation constraint binds in equilibrium. This implies that $\hat{g}_{i}=\tau_{i} y_{1}-W_{i}$ which is exactly the complete information outcome. Substituting this into the voter's budget constraint it is easy to see that, in this case, the budget set remains unchanged. Thus, when information noise is small enough, the median voter reduces the cutoff signal from $m_{i} \hat{g}_{i}$ to $m_{i} \hat{g}_{i}-a$ while leaving the tax rate unchanged. This induces the government to continue providing the certainty level of infrastructure which, in turn, is sufficient to guarantee re-election.

When $a \geq \frac{m_{i} W_{i}}{2}$, we can use equation (26) to rewrite the participation constraint for a type $i$ government as

$$
\hat{s}_{i}-a=m_{i} \tau_{i} y_{1}-z_{i} a^{1 / 2}, \quad i=H, L
$$

Substituting (29) into (25) and rearranging yields

$$
g=\tau_{i} y_{1}-\frac{\left(2 a m_{i} W_{i}\right)^{1 / 2}}{m_{i}}
$$

where we have used the definition of $z$ given above. Substituting (30) into the period 1 budget constraint for the household gives

$$
c_{1}(i)=y_{1}-\frac{\left(2 a m_{i} W_{i}\right)^{1 / 2}}{m_{i}}-\hat{g}_{i}
$$

which is the agent's first period consumption under a type $i$ government. Note that the second period budget constraint remains the same as in the certainty case.

It is easy to see that for $a \geq \frac{m_{i} W_{i}}{2}$, first period disposable income under incomplete information is smaller than under complete information, i.e., $y_{1}-\frac{\left(2 a m_{i} W_{i}\right)^{1.12}}{m_{i}} \leq y_{1}-W_{i}$, given the same type $i$ government. This difference in disposable income is a measure of the incremental agency cost of government due to private information. One consequence of this added cost is the reduction in infrastructure provision implied by equation (30). We collect these results in the following proposition:

Proposition 3. Infrastructure provision under incomplete information is smaller than under complete information if $a>\frac{m_{i} W_{i}}{2}$. Otherwise outcomes under incomplete and complete information are identical. 
Proposition 3 says that the agency costs of intermediation become positive when information is sufficiently noisy. Voters will compensate the incumbent for putting up with the risk of being voted out of office because of a bad signal in some states of nature. This extra payment is the agency cost of infrastructure provision through an intermediary whose actions are imperfectly observed. The agency costs reduce first period disposable income and desired savings.

In order to analyze how imperfect observability influences the actual choice of government, we return to the iso-elastic class of preferences given by equation (13) and to the convenient normalization of the income vector from $\left(y_{1}, y_{2}\right)$ to $(\lambda, \lambda y)$. Using the indirect utility function of the representative voter from equation (15), we derive the voter's lifecycle utility under each government type:

$$
\begin{gathered}
(1-\theta) V^{L}(\lambda, a)= \begin{cases}{\left[1-\frac{W_{L}}{\lambda}+\frac{y}{m_{L}}\right]} & \text { if } a<\frac{m_{L} W_{L}}{2} \\
{\left[\lambda-\frac{\left(2 a m_{L} W_{L}\right)^{1 / 2}}{m_{L}}+\frac{\lambda y}{m_{L}}\right]^{1-\theta} g\left(m_{L}\right)} & \text { if } a \geq \frac{m_{L} W_{L}}{2}\end{cases} \\
(1-\theta) V^{H}(\lambda, a)= \begin{cases}{\left[1-\frac{W_{H}}{\lambda}+\frac{y}{m_{H}}\right]} & \text { if } a<\frac{m_{H} W_{H}}{2} \\
{\left[\lambda-\frac{\left(2 a m_{H} W_{H}\right)^{1 / 2}}{m_{H}}+\frac{\lambda y}{m_{H}}\right]^{1-\theta} g\left(m_{H}\right)} & \text { if } a \geq \frac{m_{H} W_{H}}{2}\end{cases}
\end{gathered}
$$

where $\lambda$ is again the scale of the economy. The payoff ratio is defined, as before, by $\psi(\lambda) \equiv V^{H}(\lambda) / V^{L}(\lambda)$. Note that $\psi$ is now a function of both $\lambda$ and the noise in the information process, $a$. It is easy to show (see Appendix):

Lemma 6. $\psi$ is independent of $a$ if $a \in\left[0, \frac{m_{L} W_{L}}{2}\right]$; it is increasing in $a$ if $a \in\left[\frac{m_{L} W_{L}}{2}, \frac{m_{H} W_{H}}{2}\right]$ and decreasing in $a$ if $a>\frac{m_{H} W_{H}}{2}$ and $\frac{W_{L}}{W_{H}}<\left(\frac{m_{L}}{m_{H}}\right)\left(\frac{1+\left(y / m_{L}\right)}{1+\left(y / m_{H}\right)}\right)^{2}$.

Lemma 6 explains how the low cost advantage of the low ability type increases with greater information noise and higher agency costs as long as the information process is "sufficiently noisy", i.e., $a>\frac{m_{H} W_{H}}{2}$. This occurs because a high ability government has a greater agency cost than does a low ability government. The higher reservation consumption level of a good government requires that it should be offered proportionately more compensation for running the risk of being turned out of office, and forgoing all consumption despite having chosen the "right level" of infrastructure investment. 
For very low levels of information noise, $a \in\left[0, \frac{m_{L} W_{L}}{2}\right]$, the private agent's indirect utility, says equation (17), is independent of $a$. In this case the economy reproduces the complete information outcome. In the intermediate noise range, $a \in\left[\frac{m_{L} W_{L}}{2}, \frac{m_{H} W_{H}}{2}\right]$, imperfect observability has a second-best influence. In this range the economy reproduces the certainty outcome if it chooses a high ability government. On the other hand, a low ability government implies that tax revenues are needed to pay agency costs over and above the intermediation cost, $W_{L}$. This shrinks the cost advantage of the low ability type and makes the high quality government more attractive to the voter.

Let $\lambda_{C}$ denote the critical scale of the economy above which high ability governments are elected under complete observability. Let $\lambda_{I}$ denote the corresponding critical scale under incomplete observability of government types and actions. Assuming that $\frac{W_{L}}{W_{H}}<\frac{m_{L}}{m_{H}} \frac{1}{\alpha^{2}}$ where $\alpha \equiv\left(\frac{g\left(m_{L}\right)}{g\left(m_{H}\right)}\right)^{\frac{1}{1-\theta}}<1$, we can state the following proposition:

Proposition 4. The critical scale of the economy remains independent of the information noise index $a$ if $a \leq \frac{m_{L} W_{L}}{2}$. For $a \in\left[\frac{m_{L} W_{L}}{2}, \frac{m_{H} W_{H}}{2}\right]$, the critical scale is lower under private information. For all $a \geq a^{*}>\frac{m_{H} W_{H}}{2}$, the critical scale is higher under private information.

Proof. See the Appendix.

Proposition 4 is at the heart of this section. It says that, if the information process is sufficiently noisy, additional noise raises the agency cost of good government. On the other hand, noise has no marginal effect on the economy if it exists in very small amounts. In the intermediate range for the noise parameter, we have a perverse second-best result: imperfect information actually helps the prospects of good governance by increasing the costs associated with electing a low ability government while the corresponding cost of a high ability type remains unchanged.

Our results highlight the importance of an informed electorate for the quality of governance. In particular, a high degree of information noise may induce even relatively rich economies to choose low quality governments. On the other hand, poorer economies might find high ability governments affordable if the information structure of the economy is sufficiently developed and reliable. This suggests an economic reason (over and above the conventional human rights reasons) for the desirability of a free press and low cost information dissemination. 


\section{Cross-Country Evidence}

The theoretical analysis above makes two primary predictions regarding the choice of governments. First, it predicts that as countries become richer they will tend to choose better governments if the costs of government (the intermediation costs) rise less than proportionately with income. Second, the theory suggests that, as the electorate becomes better informed about the economy, the country will tend to choose better governments because better information reduces the agency costs of good governments.

In order to explore the realism of the first channel, i.e., the decreasing costs of government assumption, we examined the share of wages and salaries in the central government budget across a wide range of countries. To fix ideas regarding the precise predictions of the model, we return to the perfect information case and rewrite the participation constraint of the government agent (equation (3)) in terms of the government budget shares of wages and infrastructure investment to get $1=\left(W_{i} / \tau_{i} y_{1}\right)+\left(\mathrm{g}_{\mathrm{i}} / \tau_{i} y_{1}\right), i=H, L$. Since $g$ rises as $y_{1}$ rises while $W$ remains fixed, $\tau_{i} y_{1}$ must rise with first period income if the participation constraint is to hold. Hence, $W_{i} / \tau_{i} y_{1}$ will fall as $y_{1}$ rises. Because $\tau_{i} y_{1}$ represents total government revenues and expenditure, our theory predicts that, given a government type, we should expect the share of wages and salaries in the government budget to shrink as per capita income rises.

Figure 8 plots wages and salaries as a percentage of central government expenditures against per capita GNP for 78 countries. One can see that the central government budget share of wages and salaries decreases as per capita income rises. The correlation coefficient between the two variables is -0.46 . This lends some support to our hypothesis of decreasing costs of government intermediation. However, Figure 8 also shows that at low levels of per capita GNP there is greater dispersion in the wage share of the government budget across countries. This accounts for the low $\mathrm{R}^{2}$ reported in the figure.

A natural criticism regarding the applicability of this evidence to the theory is that the model predicts that controlling for a government type, the cost of government should be a decreasing function of income. However, the model also predicts that richer countries should elect better (more efficient) governments which entails higher wage costs. Hence, the model does not unconditionally predict that richer countries have lower costs of government. In order to investigate this issue a little more closely, we regressed the wage share of government expenditure against per capita GNP and the index of bureaucratic efficiency. As Table 2 shows, the results seem to fit the predictions of the model. Controlling for the quality of government (proxied by the bureaucratic efficiency index), richer countries do indeed have a lower wage share in government expenditures.

The greater dispersion in the wage share at low income levels seen in Figure 8 is not entirely inconsistent with our model since the theory predicts that an independent determinant of government quality is the level of noise in the information process, which is the second channel we described above. Thus, at the same low income level, countries with very little information noise could choose good governments and high wage shares of the government budget while others with less informed voters could choose low quality governments and low wage shares. However, once income becomes sufficiently high, most countries switch to high quality governments. At this point the only factor which affects the cross-country wage share of the government budget is the decreasing cost of government as income rises. Hence, the lower variance in the wage share at higher levels of per capita GNP. 
Figure 8

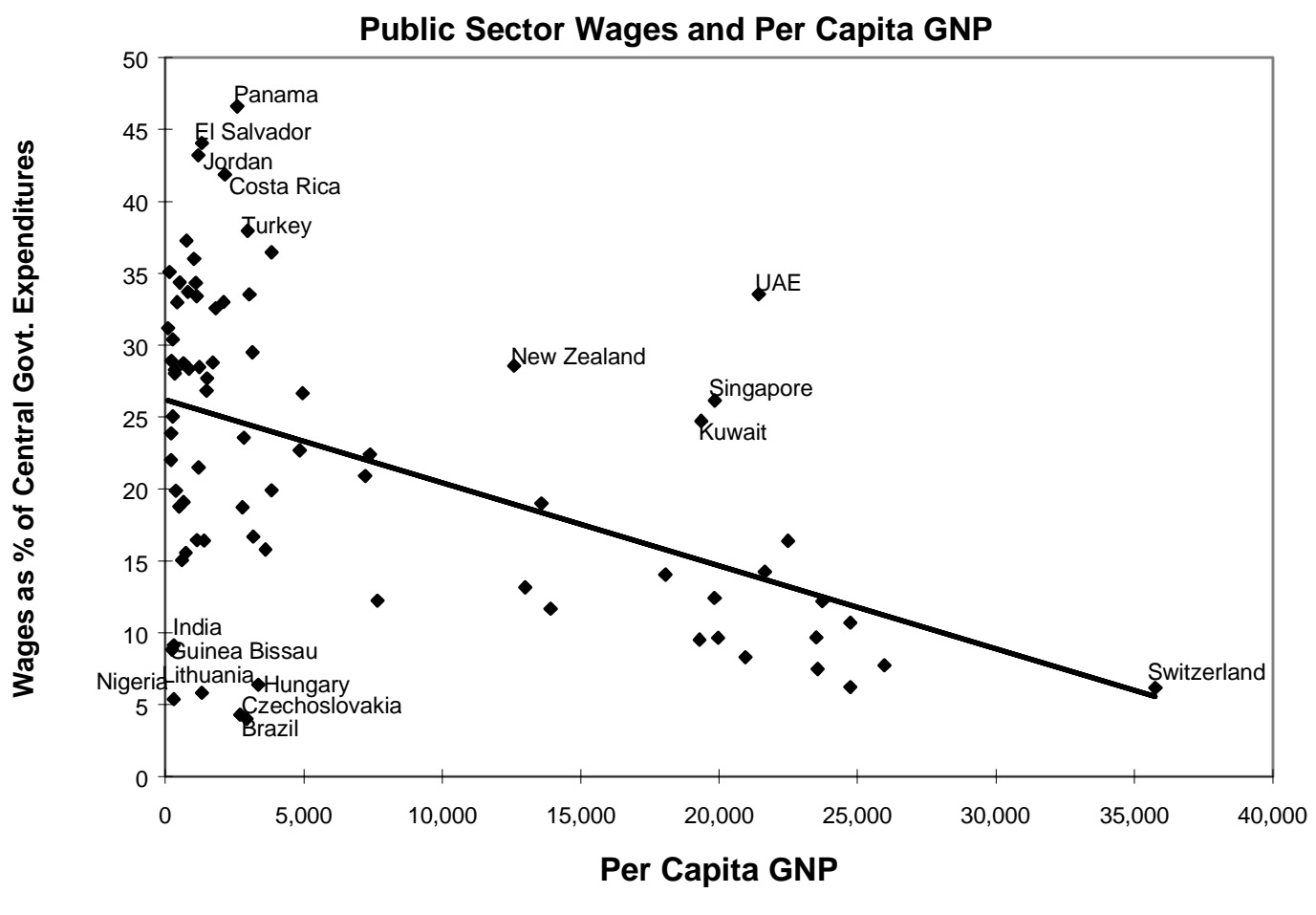

Number of Observations: $78 \quad R^{2}=0.2281$

Data source: Government Finance Statistics Yearbook, 1992, IMF 
Table 2: Regression results

Dependent variable: Share of wages in total central government outlays (percent)

\begin{tabular}{lcc}
\hline Variable & Coefficient & t-statistic \\
\hline Constant & 19.3465 & 3.4436 \\
Per capita GNP & -0.00082 & -4.0989 \\
Bureaucratic efficiency & 1.26295 & 1.2939 \\
\hline & & \\
R-squared & 0.3497 & \\
Adjusted R-squared & 0.3220 & \\
Observations & 50 & \\
\hline \hline
\end{tabular}

In order to test the predicted positive relationship between government quality and the quality of information in the economy, we need a variable that measures the ease with which voters can gather reliable information regarding government policy. Thus, we need a variable for factors such as the freedom of the press and the media, the degree of competition among newspapers and other media, freedom of speech, etc.. While precise measures for these are hard to find, one can use some proxies. We chose an index of civil liberties as our proxy for the ease with which information can be exchanged within an economy. The data on the index is reported in McMillan, Rausser and Johnson (1994) who used it to analyze the relationship between economic growth and political and civil liberties.

The index is constructed by Freedom House through a simple averaging of thirteen features of a nation's civil rights. Each item is given a score of 0,1 , or 2 based on a standardized procedure. The raw scores are then averaged and represented on a scale of 1 to 7 . A score of 1 indicates that there are no obstructions to independent expression and publication within the country while a score of 7 indicates that the country permits little independent expression, and that there is wide spread fear and a police-state environment. We use the average of the index for the period 1972 to 1988.

Figure 9 plots the civil liberties index against the bureaucratic efficiency index. As predicted by the model, the two variables are negatively correlated. Thus, as the exchange of information becomes easier and the freedom of expression and publication increases (the civil liberties index falls), the quality of governments improves (the bureaucratic efficiency index rises) across countries. The correlation coefficient between the two variables is -0.63 .

The evidence above tends to lend some support to the two primary mechanisms affecting the choice of governments studied in this essay. However, the evidence is extremely preliminary and we regard it as purely suggestive. A comprehensive verdict on the validity of the channels we discussed, including capital mobility, would require a much more detailed empirical analysis of the issues. We hope to see more work in this direction. 
Figure 9

Civil Liberties and Bureaucratic Efficiency

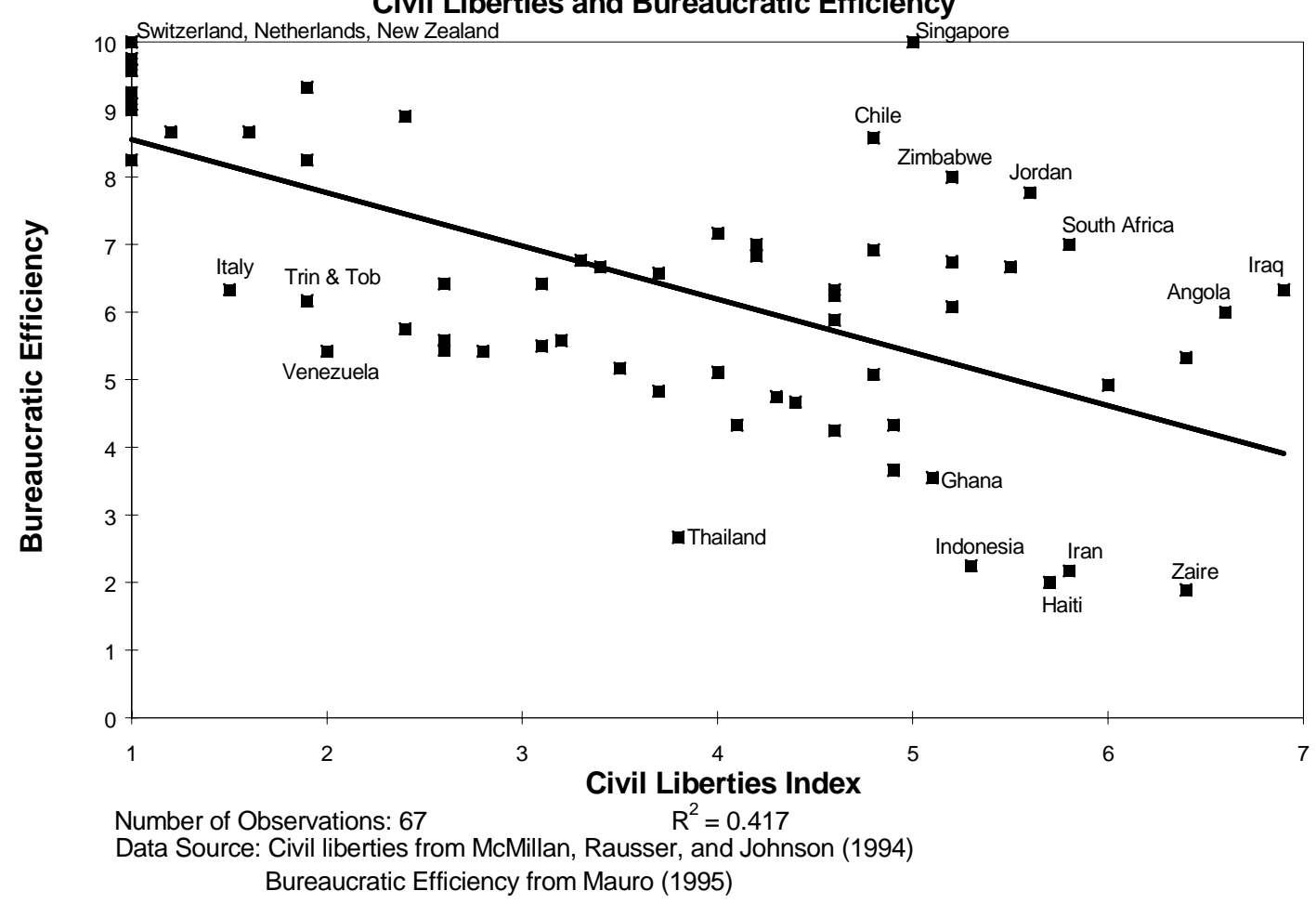




\section{Conclusions}

We have analyzed public investment in social infrastructure in a two-period principal-agent model in which public investment must be intermediated by a government. We view intermediation as a costly activity: intermediaries are wage earning consumers who do not work in the public interest unless they are paid in return. More importantly, high quality intermediaries earn higher incomes than low ability intermediaries. Thus, while good governments may invest more in infrastructure and generate better returns on their investment than do low quality governments, they are also relatively more expensive to hire and extract bigger taxes from voters.

When government quality is a direct choice variable and the cost of government intermediation per unit national income is decreasing, then elections have a threshold property. At low income levels, high ability governments are too expensive relative to low ability governments. As income grows, good governments become relatively cheaper since their reservation consumption levels do not typically grow in proportion to income. Thus, closed economies above a critical income level rationally elect high quality governments while those below that threshold choose lower quality governments just as rationally. Since income growth is itself a function of the level and productivity of infrastructure investment, economies already above the threshold tend to grow faster than those below the threshold. The model, thus, suggests a political-economy explanation for poverty traps and the continued global disparities in per capita national income.

Capital mobility is another feature which favors high quality governments because it improves an economy's ability to smooth consumption and, thus, reduces the current consumption cost of investing in infrastructure. Foreign borrowing, in particular, allows future returns to public capital to help defray the costs of building up that capital.

An informed electorate turns out to be a key factor in choosing good governments. We found that both government choice and infrastructure investment are very sensitive to the level of noise in the economy. When noise is not too large, the economy is able to reproduce the complete information outcome. Once information becomes too noisy, the intermediary function of government starts extracting agency costs over and above the direct consumption cost. This depresses infrastructure investment and biases the choice of government towards the low quality type.

Using cross-country data on the wage share of the central government budget, we found that as per capita income rises the share of wages in the central government budget declines (after controlling for the quality of government). This provides some support to our hypothesis of decreasing costs of government intermediation. We also used an index of civil liberties constructed by Freedom House as a proxy for noise in the information process or for the ease with which voters could exchange information. We found that as civil liberties improve, the quality of the bureaucracy also improves. Thus, as suggested by the theory, better informed voters are more likely to choose good governments. We interpret both bits of evidence as lending preliminary support to the determinants of government choice stressed in the paper.

The structure we studied can be extended in several directions, four of which seem particularly interesting. First, we may allow government ability to be a continuous variable either by explicitly introducing a continuum of agents or by constructing coalitions of two primary agents with varying shares in total government consumption. Second, the paper is completely silent on the issue of electoral competition (see Ordeshook (1986), ch.4, and Wittman (1989)). We have assumed that the choice of alternative intermediaries that is available to the median voter is the same independent of the level of national income. However, electoral competition amongst 
relatively high ability candidates is much stronger in richer economies relative to poorer economies.

Third, we have also ignored the issue of corruption which is an extremely costly activity from a social point of view (see Mauro (1995), and Shleifer and Vishny (1993)). In addition, richer economies are typically the ones with less graft and corruption. The fact that poorer countries have a larger wage share of total government outlays than do richer countries (even without controlling for government quality) may be a direct sign of greater corruption in poorer countries. In particular, overemployment in the public sector is one of the typical ways in which politicians buy electoral favor in most countries. We believe that corruption and electoral competition are extremely important factors in the selection of governments and the choice of public investment. Research in this area would considerably enhance our understanding of public policy formation. Fourth, we have ignored the issue of ideological differences across parties and private agents. Since infrastructure often produces public goods, the introduction of some differences in how voters evaluate these goods may be particularly helpful.

\section{Appendix}

Proof of Lemma 3. (a) For $m_{i} g_{i} \in\left[\hat{s}_{i}-a, \hat{s}_{i}+a\right]$ any efficient type $\mathrm{H}$ contract must satisfy

and

$$
\begin{aligned}
& m_{H} \tau_{H} y_{1}+a-\hat{s}_{H} \geq z_{H} a^{1 / 2} \\
& m_{L} \tau_{H} y_{1}+a-\hat{s}_{H} \leq z_{L} a^{1 / 2}
\end{aligned}
$$

where (A-1) is the participation constraint while (A-2) is the incentive compatibility constraint, both derived from equations (26) and (28). Subtracting (A-2) from (A-1) we get $\tau_{H} \geq \frac{\left(z_{H}-z_{L}\right) a^{1 / 2}}{\left(m_{H}-m_{L}\right) y_{1}} \equiv \tau *$ which proves the first part. Similarly, we can show $\tau_{L}<\tau *$. For $m_{i} g_{i}=\hat{s}_{i}+a$, the result follows analogously by using the relevant expression from (26).

For parts (b) and (c) note that any efficient type i contract must satisfy

$$
\begin{array}{cc}
\hat{W}\left(\hat{s}_{i}, \tau_{i} ; m_{i}\right) \geq W_{i} & i=H, L \\
\hat{W}\left(\hat{s}_{i}, \tau_{i} ; m_{j}\right) \leq W_{j} & j \neq i, j=H, L
\end{array}
$$

Ignoring the non-generic case of both constraints binding simultaneously, we have three possible cases: (i) (A-3) binds while (A-4) does not; (ii) (A-4) binds while (A-3) does not; and (iii) neither binds. Suppose we have an equilibrium where case (ii) holds. It is easy to see from equation (26) that both $\hat{W}\left(\sigma_{i}, m_{i}\right)$ and $\hat{W}\left(\sigma_{i}, m_{j}\right)$ are increasing in $\tau$. Further, by substituting the optimized values for $g$ into the consumer's budget constraint it is easy to check that, in the economically relevant range, the voter's lifetime utility is decreasing in $\tau_{i}$ and increasing in $\hat{s}_{i}$. Hence, $\exists \rho>0$ such that $\hat{W}\left(\hat{s}_{i}, \tau_{i}-\rho ; m_{i}\right) \geq W_{i}$ while $\hat{W}\left(\hat{s}_{i}, \tau_{i}-\rho ; m_{j}\right)<W_{j}$. Thus, both constraints are satisfied while private welfare is greater at $\tau_{i}-\rho$ since utility is decreasing in the tax rate. Hence, case (ii) can never be an equilibrium. Similarly, case (iii) can also never arise in 
equilibrium since there would exist tax cuts which were both feasible and welfare improving and which would not violate (A-3) or (A-4). The only remaining possibility is case (i) which proves the rest of this lemma.

Proof of Lemma 4. We prove it for the type $\mathrm{H}$ government. An analogous reasoning applies for the type $\mathrm{L}$ government. For $m_{i} g_{i} \in\left[\hat{s}_{i}-a, \hat{s}_{i}+a\right)$ any efficient type $\mathrm{H}$ contract with a binding participation constraint implies that (A-1) holds with equality. A binding incentive compatibility constraint under an efficient type L contract implies

$$
m_{H} \tau_{L} y_{1}+a-\hat{s}_{L}=z_{H} a^{1 / 2}
$$

It is easy to check that both (A-1) and (A-5) have the same slope and intercept and, thus, define the same straight line. Note that the same reasoning applies to the case $m_{H} g_{H}=\hat{s}_{H}+a$ except that the constraints get appropriately modified.

Proof of Lemma 5. Combining equations (20) and (21) we have

$$
2 a W\left(\sigma_{i}, m_{i}\right)=\left\{\left(m_{i} g_{i}+a-\hat{s}_{i}\right)\left(\tau_{i} y_{1}-g_{i}\right)\right\}
$$

Differentiating the above with respect to $g_{i}$ and evaluating the resulting expression at $m_{i} g_{i}=\hat{s}_{i}+a$ we get

$$
\begin{aligned}
\left.2 a \frac{\partial W\left(\sigma_{i}, m_{i}\right)}{\partial g_{i}}\right|_{m_{i} g_{i}=\hat{s}_{i}+a} & =\left\{\left(m_{i}\left(\tau_{i} y_{1}-g_{i}\right)-2 a\right\}\right. \\
& \geq m_{i} W_{i}-2 a
\end{aligned}
$$

where the second inequality follows from the participation constraint for the type $i$ government (equation (23)). This expression is positive for $a \leq \frac{m_{i} W_{i}}{2}$.

To prove the "only if" part of the lemma suppose $a>\frac{m_{i} W_{i}}{2}$ and $m_{i} g_{i}=\hat{s}_{i}+a$. As $\operatorname{Pr}\left(s_{i} \geq \hat{s}_{i}\right)=1$ in this event and since, by Lemma 3, we know that in equilibrium the participation constraint is binding, we must have $\tau_{i} y_{1}-g_{i}=W_{i}$. Substituting this into the first equality in (A7) and using $a>\frac{m_{i} W_{i}}{2}$ we have $\left.2 a \frac{\partial W\left(\sigma_{i}, m_{i}\right)}{\partial g_{i}}\right|_{m_{i} g_{i}=\hat{s}_{i}+a}<0$. But this contradicts $m_{i} g_{i}=\hat{s}_{i}+a$ since an infinitesimal reduction in the provision of $g$ increases government consumption. 
Proof of Lemma 6. For $a \in\left[0, \frac{m_{L} W_{L}}{2}\right]$ we know from Lemma 5 and Proposition 3 that incomplete observability leaves the complete observability outcomes unchanged. Hence, private welfare and $\psi$ are both independent of $a$. In addition we have

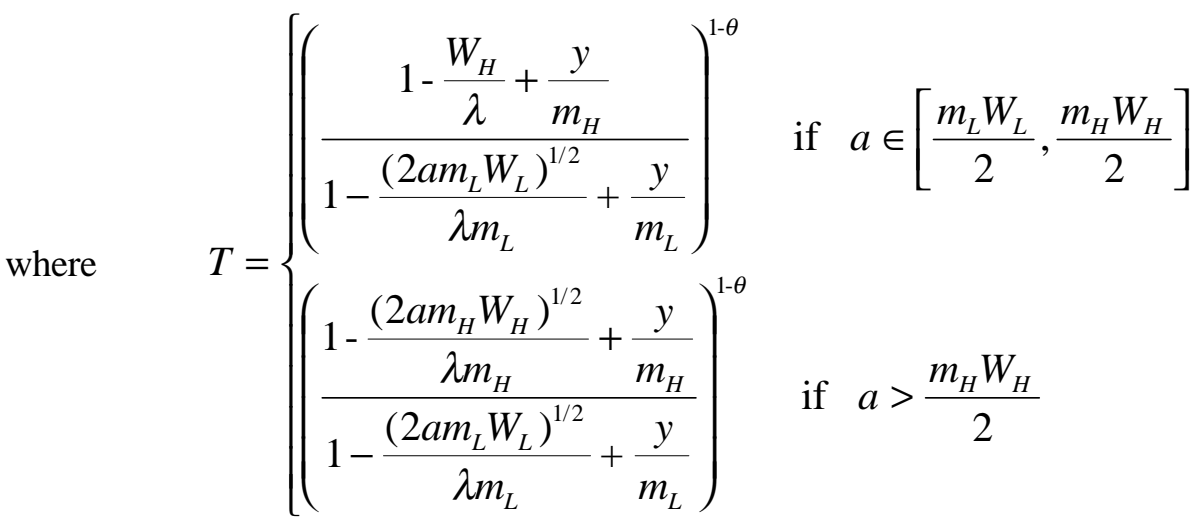

The rest of the lemma follows by differentiating (A-9) with respect to $a$.

Proof of Proposition 4. Since $\psi$ is independent of $a$ for $a \in\left[0, \frac{m_{L} W_{L}}{2}\right]$ by Lemma 6 , the first part of the proposition follows trivially. For any given $a$, the critical scale of the economy solves $\psi=1$. For $a \in\left[\frac{m_{L} W_{L}}{2}, \frac{m_{H} W_{H}}{2}\right]$ we can use the relevant expression for $T$ from (A-9) and set the right hand side of (A-8) equal to 1. After some algebraic manipulations we get

$$
\lambda_{I}=\frac{W_{H}-\alpha \frac{\left(2 a m_{L} W_{L}\right)^{1 / 2}}{m_{L}}}{1+\frac{y}{m_{H}}-\alpha\left(1+\frac{y}{m_{L}}\right)}<\frac{W_{H}-\alpha W_{L}}{1+\frac{y}{m_{H}}-\alpha\left(1+\frac{y}{m_{L}}\right)}=\lambda_{C}
$$

where $\alpha \equiv\left(\frac{g\left(m_{L}\right)}{g\left(m_{H}\right)}\right)^{\frac{1}{1-\theta}}<1$. For $a>\frac{m_{H} W_{H}}{2}$ the corresponding expression for $\lambda_{I}$ is 


$$
\lambda_{I}=\frac{\frac{\left(2 a m_{H} W_{H}\right)^{1 / 2}}{m_{H}}-\alpha \frac{\left(2 a m_{L} W_{L}\right)^{1 / 2}}{m_{L}}}{1+\frac{y}{m_{H}}-\alpha\left(1+\frac{y}{m_{L}}\right)}
$$

We know from (A-10) that $\lambda_{I}<\lambda_{C}$ at $a=\frac{m_{H} W_{H}}{2}$. Further, a necessary and sufficient condition for the numerator of the right hand side of (A-11) to be increasing in $a$ is $\frac{W_{L}}{W_{H}}<\frac{m_{L}}{m_{H}} \frac{1}{\alpha^{2}}$ which is the maintained assumption. Thus, $\exists$ an $a^{*}>\frac{m_{H} W_{H}}{2}$ such that $\lambda_{I}\left(a=a^{*}\right)=\lambda_{C}$ and $\lambda_{I}>\lambda_{C} \forall a>a^{*}$.

\section{References}

Aschauer, D., 1989, “Is Public Expenditure Productive?" Journal of Monetary Economics, 23, pp. 177-200.

Azariadis, C., 1996, “The Economics of Poverty Traps,” Journal of Economic Growth, 1, pp. 449486.

and A. Drazen, 1990, "Threshold Externalities in Economic Development," Quarterly Journal of Economics, 105, pp. 501-26.

Barro, R., and X. Sala-i-Martin, 1995, Economic Growth, New York: McGraw Hill.

Benhabib, J., and J. Gali, 1995, "On Growth and Indeterminacy: Some Theory and Evidence," forthcoming in Carnegie-Rochester Series on Public Policy. and A. Rustichini, 1996, "Social Conflict and Growth," Journal of Economic Growth, 1, pp. 125-142.

Canning, D., and M. Fay, 1993, "The Effect of Transportation Networks on Economic Growth," Columbia University Working Paper, New York.

Chari, V.V., P. Kehoe and E. McGrattan, 1995, "The Poverty of Nations: A Quantitative Exploration," mimeo, Federal Reserve Bank of Minneapolis.

Easterly, W., and S. Rebelo, 1993, "Fiscal Policy and Economic Growth: An Empirical Investigation," Journal of Monetary Economics, 32 (2), 417-458. 
Galor, O., and H. Ryder, 1989, "Existence, Uniqueness and Stability of Equilibrium in an Overlapping-Generations Model With Productive Capital," Journal of Economic Theory, 49, pp. 360-75.

Grier, K., and G. Tullock, 1989, "An Empirical Analysis of Cross-National Economic Growth, 1951-80,” Journal of Monetary Economics, 24, pp. 249-276.

Mankiw, G., D. Romer and D. Weil, 1992, "A Contribution to the Empirics of Economic Growth," Quarterly Journal of Economics, 107, pp. 407-37.

Matsuyama, K., 1991, "Increasing Returns, Industrialization, and Indeterminacy of Equilibrium," Quarterly Journal of Economics, 106, pp. 617-50.

Mauro, P., 1995, “Corruption and Growth,” Quarterly Journal of Economics, 110, pp. 681-712.

McMillan, J., G. Rausser, and S. Johnson, 1994, "Economic Growth, Political and Civil Liberties," International Center for Economic Growth, Occasional Papers No. 38.

Ordeshook, P., 1986, Game Theory and Political Theory: An Introduction, Cambridge, U.K., Cambridge University Press.

Peltzman, S., 1980, "The Growth of Government," Journal of Law and Economics, 23, pp. 209287.

Quah, D., 1996, "Convergence Empirics Across Economies With (Some) Capital Mobility," Journal of Economic Growth, 1, pp. 95-124.

Shleifer, A., and R. Vishny, 1993, "Corruption,” Quarterly Journal of Economics, 108, pp. 599617.

Wittman, D., 1989, "Why Democracies Produce Efficient Results," Journal of Political Economy, 97, pp. 1395-1424. 